\title{
Non-Human Papillomavirus-Related Penile Intraepithelial Neoplasia
}

National Cancer Institute

\section{Source}

National Cancer Institute. Non-Human Papillomavirus-Related Penile Intraepithelial

Neoplasia. NCI Thesaurus. Code C162536.

Intraepithelial neoplasia of the penis that is not caused by human papillomavirus infection. 